Dr Bauer, Professor Linderkamp, and Professor Versmold comment:

Drs Wright and Goodall present blood volume and mean arterial blood pressure (MABP) measured in 31 very low birthweight infants. No relationship was found between blood volume and MABP over a blood volume range of $46-131 \mathrm{ml} / \mathrm{kg}$. The authors measured MABP by an invasive method, whereas we determined systolic blood pressure (SBP) by an invasive method in 14 infants and by oscillometry in 29 infants. ${ }^{1}$ We observed a significant overall third order polynomial function between SBP and blood volume $(r=0.54 ; \mathrm{p}<0.001)$ due to increased SBP in infants with blood volume $>100 \mathrm{ml} / \mathrm{kg}$ (59 (9) $\mathrm{mm} \mathrm{Hg}$ ) when compared with infants with blood volume $<100 \mathrm{ml} / \mathrm{kg}$ (48 (7) $\mathrm{mm}$ $\mathrm{Hg}$ ). Drs Wright and Goodall suggest that the different results of the two studies may be due to the use of osciilometry in the majority of SBP measurements. In our study, only two out of 10 infants with blood volume $>100$ $\mathrm{ml} / \mathrm{kg}$ had their SBP measured by an invasive method. Moreover, separate analysis of the relationship between SBP and blood volume showed a significant relationship only for SBP measured by oscillometry. It may, therefore, be argued that SBP was overestimated in the infants with high blood volume.

Problems associated with oscillometry have been summarised by Weindling. ${ }^{2}$ Inflation of the cuff may disturb the infant. Oscillometry tends to overestimate blood pressure when the infant is hypotensive. ${ }^{3}$ Sonesson and Broberger observed that by using a cuff width to arm circumference ratio of $0.33-0.42$, SBP is overestimated by 7 (11) $\mathrm{mm} \mathrm{Hg}$, whereas the error is only +1 (5) when a cuff width to arm circumference ratio of $0.44-0.55$ is used. ${ }^{4}$ In our study, the cuff width to arm circumference ratio was always between 0.44 and 0.55 . In hypotensive infants, oscillometry may give normal instead of low blood pressure readings, but not abnormally high values. ${ }^{3}$ It appears unlikely that infants with high blood volume were more disturbed by cuff inflation than infants with normal or low blood volume. Thus, we believe that the oscillometric blood pressure recordings were reliable.

It is important to stress that both studies agree that arterial blood pressure alone is a poor indicator of hypovolaemia in very low birthweight infants.

1 Bauer K, Linderkamp O, Versmold HT. Systolic blood pressure and blood volume in preterm infants. Arch Dis Child 1993; 69: 521-2.

2 Weindling AM. Blood pressure monitoring in the newborn. Arch Dis Child 1989; 64: 444-7.

3 Diprose GK, Evans DH, Archer LNS, Levene MI. Dinamap fails to detect hypotension in very low birthweight babies. Arch Dis Child 1986; 61: 771-3.

4 Sonesson SE, Broberger U. Arterial blood pressure in the very low birthweight neonate. Acta Paediatr Scand 1987; 76: 338-41.

\section{Patent ductus arteriosus in the newborn}

EDITOR,-We read Nick Archer's recent paper with interest. ${ }^{1}$ We thought that it was a helpful paper but feel that we must comment on some of Dr Archer's recommendations regarding fluid intake in the newborn.

Dr Archer suggests that 'fluid intakes greater than $140 \mathrm{ml} / \mathrm{kg} / 24$ hours ... are inadvisable' without distinguishing between sodium and water. The evidence linking fluid volumes with certain neonatal problems is incomplete and does not separate sodium and water. Coulthard and Hey have shown that preterm babies are able to cope with widely varying water intakes provided that their sodium intake is kept constant. ${ }^{2}$ The recommendation to treat preterm babies who have symptomatic patent ductus arteriosus (PDA) with 'fluid restriction' is based on retrospective studies that failed to take into account sodium input and as far as we are aware there have been no prospective randomised trials to show that it is an effective treatment.

Advice to limit fluid intake without further qualification may be harmful in certain circumstances. Nutritional intake is reduced to a significant degree and prolonged restriction of fluid volumes is a serious cause of suboptimal nutrition in neonatal intensive care units. Many extremely immature babies have high insensible water losses, and failure to keep up with water loss will lead to hypernatraemic dehydration. Further, when treating a PDA, dehydration will exacerbate indomethacin toxicity.

The age of the baby at the time of discovery of the PDA is also important. There is a postnatal maturation in the ability to handle a sodium $\operatorname{load}^{3}$ and clinical management should take account of this.

Dr Archer suggests that a symptomatic PDA would rarely be missed if clinical signs are looked for regularly. However, evidence suggests that clinical assessment is insensitive. ${ }^{4}$ The profession is indebted to Dr Archer for having done so much to introduce echocardiography into the neonatal intensive care unit but we suggest that we should look to see echocardiography progress into an essential tool for all competent neonatologists in much the same way that cranial ultrasound scanning has progressed from a specialised to a generalised skill

GARY HARTNOLL PIERRE BETREMIEUX NEENA MODI

Department of Paediatrics and Neonatal Medicine, Hammersmith Hospital,
Du Cane Road, Du Cane Road,
London W12 ONN

1 Archer N. Patent ductus arteriosus in the newborn. Arch Dis Child 1993; 69: 529-32.

2 Coulthard MG, Hey EN. Effect of varying water intake on renal function in healthy preterm babies. Arch Dis Child 1985; 60: 614-20.

3 Modi N. Sodium intake and preterm babies. Arch Dis Child 1993; 69: 87-91.

4 Walther FJ, Kim DH, Ebrahimi M, Siassi B. Pulsed Doppler measurements of left ventricular output as early predictor of symptomatic patent ductus arteriosus in very preterm infants. Biol Neonate 1989; 56: 121-8.

\section{Dr Archer comments:}

Some enlargement of the statement with respect to limiting fluid intake to not more than $140 \mathrm{ml} / \mathrm{kg} / 24$ hours is certainly helpful. That figure came from a paper in which the smallest baby was $751 \mathrm{~g}$. Now, babies much smaller than this receive successful intensive care and fluid and sodium requirements, of course, have to be individualised and will, among other things, be determined by the environment in which the infant is nursed. The comments by the Hammersmith group are, therefore, relevant. However, I should point out that I was referring to prevention of symptomatic PDA in the first week of life and not treatment of the condition, nor was I recommending prolonged restriction.

Hartnoll and colleagues refer to the paper by Walther et al ${ }^{1}$ as proof that clinical assessment is insensitive in detecting symptomatic PDA. What Walther et al actually demonstrated was that Doppler echocardiography can be used as a predictor for the development of symptomatic patent ductus which is different matter.
The brief for the paper I wrote was a practical approach to PDA in the newborn nursery of the district general hospital where echocardiography would not normally be available. Even if it were available, the assessment used by Walther et al is quite a difficult one for occasional users to master, although I do agree with Hartnoll and colleagues that neonatologists should be developing echocardiographic skills.

1 Walther FJ, Kim DH, Ebrahimi M, Siassi B. Pulsed Doppler measurements of left ventricular output as early predictor of symptomatic patient ductus arteriosus in very preterm infants. Biol Neonate 1989; 56: 121-8.

\section{Clinical trials and neonatal intensive} care

EDITOR,-The Department of Health now acknowledges that randomised clinical trials are an essential part of routine practice and will lead to improved medical care for patients. $^{1}$ The observation has also been made that participants in a clinical trial have better outcomes than non-participants, regardless of the arm of the trial to which they are assigned. ${ }^{2}$ Randomised clinical trials therefore confer benefit upon both populations and individuals. It follows that there is a moral obligation upon clinicians to advise their patients to enter randomised trials.

In neonatal intensive care, consent to enter a baby into a trial is sought from the parents. They have just had a baby and their baby is critically ill. They are asked to listen to complex medical arguments which spell out the uncertainties of treatment and they are asked to make a positive decision to consent that their baby is entered into a trial. In addition, in academic units, it is likely that, given the relatively small numbers of babies receiving intensive care, each infant may be suitable for entry into more than one trial, for each of which consent must be sought. Many parents in this situation find it easier to make no decision and so their baby is not entered.

There are a number of issues here that deserve further scrutiny. Parents clearly have a right to know about their baby's care, but it is cruel to present them with a mass of complex medical information at a time when they are already frightened and confused. The neonatal paediatrician also has an obligation to act in the best interests of his or her patient and so it must be unethical to reduce the chances of a baby's entry into a randomised trial, given the advantages it is accepted that this will bring. Is there a way out of these dilemmas?

Education of the public in the concept and importance of randomised clinical trials has been advocated. ${ }^{3}$ Other options might also be considered. If a trial sets out to compare two treatment strategies, each of which is regarded as acceptable clinical practice and each of which individually might be implemented without parental consent, then it should be legitimate to randomise a baby without parental consent. An example might be a trial comparing antibiotic policies, each of which might be used as treatment without parental consent. Such an approach would clearly be inappropriate in, for example, a trial comparing conventional versus operative treatment, as operative treatment may only be given with parental consent. This approach would avoid having to force parents to grapple with issues that would not normally be presented to them and the equally morally questionable practice of forcing parents to 